\title{
Portal da Transparência: do que se diz e o que se faz com o cartão de pagamento do governo federal
}

\author{
Transparency Portal: what is said and what is done with the federal \\ government payment card
}

\section{Ewerton Fernandes Rafael Pereira de Fontes ${ }^{1}$ Eliabe Roberto de Souza ${ }^{2}$ Alessandra Carla Ceolin ${ }^{3}$ Liliane Aparecida da Silva Santos ${ }^{4}$}

\section{RESUMO}

Com a criação do Portal da Transparência do Governo Federal, a sociedade brasileira passou a dispor de uma nova ferramenta para suprir a demanda sobre o controle social. O objetivo geral desta pesquisa foi analisar como o Portal da Transparência do Governo Federal proporciona a transparência dos dados sobre a utilização dos recursos públicos com o uso de Cartão de Pagamento do Governo Federal no ano de 2019. Esta pesquisa teve caráter exploratório, os dados foram obtidos por meio do Painel "Cartões de Pagamentos" do Portal da Transparência e foram analisados em categorias temáticas ou unidades de análise. Os resultados revelam que o Portal da Transparência do Governo Federal disponibiliza dados sobre a utilização do Cartão de Pagamento do Governo Federal, porém existe um descompasso quanto à finalidade do uso do cartão de pagamento, que é o suprimento de fundos e o atendimento a eventuais despesas. Conclui-se,

1 Bacharel em Administração Pública. Unidade Acadêmica de Educação a Distância e Tecnologia (UAEADTec). Universidade Federal Rural de Pernambuco (UFRPE). E-mail: ewerton_315@hotmail.com. ORCID: https://orcid.org/0000-0002-6900-5323.

2 Professor mestre e pesquisador na Unidade Acadêmica de Educação a Distância e Tecnologia (UAEADTec). Universidade Federal Rural de Pernambuco (UFRPE). E-mail: elroso2009@gmail.com. ORCID: https:// orcid.org/0000-0001-6095-3151.

3 Professora doutora vinculada ao Departamento de Administração e aos Programas de Pós-Graduação em Controladoria e ao Mestrado Profissional em Administração Pública da Universidade Federal Rural de Pernambuco (UFRPE). E-mail: alessandra.ceolin@ufrpe.br. ORCID: http://orcid.org/0000-0003-3892-8712 .

4 Mestre em Gestão Pública para o Desenvolvimento do Nordeste (UFPE/2013), bacharel em Administração (UFPE/2010). Atua como tutora virtual e professora formadora no Bacharelado em Administração Pública da UFRPE desde o semestre de 2013.2. E-mail: lilianeasantos@ymail.com. ORCID: https://orcid.org/0000-00030526-2184. 
com esta pesquisa, que o Portal da Transparência permite a divulgação dos gastos públicos federais e com tal prática é possível verificar a falta de publicidade de determinados órgãos que usam o Cartão de Pagamento do Governo Federal, o descumprimento no atendimento a eventuais despesas e a ausência de planejamento no uso dos recursos públicos.

Palavras-chave: Acesso à informação. Controle social. Gestão pública. Transparência pública.

\section{ABSTRACT}

With the creation of the Transparency Portal of the Federal Government, Brazilian society now has a new tool to meet the demand on social control. The general objective of this research was to analyze how the Transparency Portal of the Federal Government provides transparency of data on the use of public resources with the use of Payment Card of the Federal Government in 2019. This research was exploratory, the data were obtained through the "Payment Cards" Panel of the Transparency Portal and were analyzed in thematic categories or units of analysis. The results reveal that the Transparency Portal of the Federal Government provides data on the use of the Payment Card of the Federal Government, but there is a mismatch as to the purpose of using the payment card, which is the supply of funds and meeting possible expenses. It is concluded with this research that the Transparency Portal allows the disclosure of federal public spending and with this practice it is possible to verify the lack of publicity of certain agencies that use the Payment Card of the Federal Government, noncompliance in meeting possible expenses and lack of planning in the use of public resources.

Keywords: Access to information. Social control. Public management. Public transparency.

Recebido: 03-02-2021

Aprovado: 16-03-2021 


\section{INTRODUÇÃO}

Em um mundo de muitas mudanças econômicas, sociais, climáticas, biológicas, tecnológicas, governamentais, e que tem passado por constantes processos de globalização, o acesso às informações torna-se imprescindível para o enfrentamento de novos contextos.

No passado, esse processo de acessibilidade e de disponibilização de informações dos conteúdos públicos e privados se dava de forma lenta, burocrática e defasada; porém, com o advento da rede mundial de computadores e suas facilidades de acesso, esse cenário vem, aos poucos, tomando outros rumos.

O acesso aos atos da Administração Pública passa a ser uma realidade nacional desde a promulgação da Constituição da República Federativa do Brasil de 1988, quando os artigos 70, 71 e 73 apresentam as instâncias responsáveis pelo controle interno e controle externo, no que diz respeito ao controle dos recursos públicos e como forma de participação ativa da sociedade (BRASIL, 1988).

De acordo com a Lei Complementar $\mathrm{n}^{\circ} 101$, de 4 de maio de 2000, que "estabelece normas de finanças públicas voltadas para a responsabilidade na gestão fiscal e dá outras providências", o art. $1^{\circ}, \S 1^{\circ}$, um dos princípios que norteiam os atos da Administração Pública e sua respectiva gestão, relaciona-se à questão da responsabilidade na gestão fiscal e à necessidade da transparência nas ações e atos praticados por ela (BRASIL, 2000).

Depreende-se, com a Lei Complementar $n^{\circ}$ 101/2000, que todos os cidadãos têm o direito de saber como é realizada a utilização do dinheiro vindo dos cofres públicos, seja na esfera municipal, estadual ou federal. $\mathrm{O}$ art. $1^{\circ}$ ainda cita a necessidade do acesso à informação como prevenção de riscos e correção de desvios capazes de afetar o equilíbrio das contas públicas, mediante o cumprimento de metas de resultados entre receitas e despesas, obediência aos limites e às condições no que tange à renúncia de receita, à geração de despesas com pessoal, da seguridade social, dí- 
vidas consolidadas e mobiliárias, operações de crédito, inclusive por antecipação de receita, concessão de garantia e inscrição em restos a pagar (BRASIL, 2000).

$\mathrm{O}$ art. 48 da Lei Complementar $n^{\circ}$ 101/2000 concretiza a necessidade de transparência nos atos públicos e assegura esse direito à população, ao instituir instrumentos de transparência da gestão fiscal, aos quais será dada ampla divulgação, inclusive em meios eletrônicos de acesso público, a planos, orçamentos e leis de diretrizes orçamentárias; às prestações de contas e ao respectivo parecer prévio; ao Relatório Resumido da Execução Orçamentária e ao Relatório de Gestão Fiscal; e às versões simplificadas desses documentos (BRASIL, 2000).

A transparência nos atos da gestão pública é de suma importância para a sociedade em geral e deve ser tratada como uma grande conquista social, pois, por meio dela, é possível acompanhar os gastos feitos por atores políticos e gestores públicos, bem como é possível identificar onde os recursos públicos são investidos e/ou utilizados.

No ano de 2009, foi instituída a Lei Complementar n ${ }^{\circ}$ 131, de 27 de maio, alterando o art. 48 da Lei Complementar $n^{\circ} 101 / 2000$, a qual passa a assegurar a transparência mediante a participação popular por meio de audiências públicas, durante os processos de elaboração e de discussão dos planos, lei de diretrizes orçamentárias e orçamentos, bem como liberando ao "[...] pleno conhecimento e acompanhamento da sociedade, em tempo real, de informações pormenorizadas sobre a execução orçamentária e financeira, em meios eletrônicos de acesso público" (BRASIL, 2009).

Com a criação do Portal da Transparência do Governo Federal pelo Ministério da Transparência e Controladoria-Geral da União em 2004 (BRASIL, 2020), a sociedade brasileira passou a dispor de uma nova ferramenta para suprir a demanda sobre o controle social. Sabe-se, pois, que o governo federal realiza compras com cartões de pagamentos, porém questiona-se: será que o Portal da Transparência do Governo Federal permite ao cidadão acompanhar a aplicação do dinheiro público federal, 
dispor de informações para o controle social e, assim, promover a transparência dos gastos públicos?

Com o aumento e o avanço da globalização, o acesso às informações se difundiu de forma amplificada. No campo da gestão pública, percebeu-se, cada vez mais, a crescente necessidade de a sociedade ter acesso às informações sobre o âmbito político e financeiro da Administração Pública, na qual os recursos financeiros vindos dos cofres públicos são investidos e gastos pelos atores políticos e gestores públicos para cumprirem e/ ou desempenharem as suas funções de forma eficiente e eficaz com vistas à adequada gestão pública.

Autores como Kondo et al. (2002), Freire (2014), Gama e Rodrigues (2016), Castro Junior (2018), Michener, Contreras e Niskier (2018) e Guimarães (2019) têm se debruçado sobre a transparência pública e o controle social, todavia percebe-se que há uma lacuna sobre a temática em estudo no que diz respeito à utilização de Cartão de Pagamento $(\mathrm{CP})$ pelo governo federal.

Instituído sob o Decreto $\mathrm{n}^{0} 5.355$, de 25 de janeiro de 2005, o Cartão de Pagamento do Governo Federal (CPGF) passa a ser uma nova forma de aquisição e de pagamento semelhante à do setor privado de acordo com o disposto no art. 15, inciso III, da Lei $n^{\circ}$ 8.666/93 (BRASIL, 2005).

Os artigos $1^{\circ}$ e $2^{\circ}$ do Decreto $n^{\circ} 5.355 / 05$ preveem o uso do CPGF pelos órgãos e entidades da Administração Pública Federal, que integram o orçamento fiscal e a seguridade social, para pagamentos de despesas realizadas com aquisição de materiais e contratação de serviços enquadrados como suprimento de fundos. O CPGF é concebido como um instrumento de pagamento, emitido em nome da unidade gestora e operacionalizado por instituição financeira autorizada, e utilizado exclusivamente pelo portador nele identificado (BRASIL, 2005).

Por outro lado, entende-se que a gestão fiscal pressupõe uma ação planejada, transparente, e o Portal da Transparência do Governo Federal passa a ser visto como uma ferramenta poderosa, com o objetivo de di- 
vulgar as informações públicas para a sociedade e para a efetivação do controle social.

O exercício de fiscalização sobre os recursos públicos ocorre por meio do controle institucional e do controle social. Salienta-se, pois, que o controle social também pode ocorrer por iniciativa do ente público, como é o caso do Portal da Transparência.

Assim, o objetivo geral desta pesquisa foi analisar como o Portal da Transparência proporciona a divulgação dos dados sobre a utilização dos recursos públicos com o uso de Cartão de Pagamento do Governo Federal como ferramenta aliada ao controle social e à prestação das contas dos gastos públicos no ano de 2019.

Decorrem do objetivo geral os seguintes objetivos específicos: investigar como o Portal da Transparência disponibiliza a oferta de dados sobre o uso do CP de acordo com legislação vigente sobre a transparência pública; elencar os órgãos superiores e as entidades vinculadas que utilizaram o cartão de pagamento em 2019; identificar os estabelecimentos e os favorecidos com a utilização do Cartão de Pagamento do Governo Federal; e apresentar as despesas realizadas com Cartão de Pagamento pelo Governo Federal com vistas ao controle social.

\section{REFERENCIAL TEÓRICO}

A transparência e a responsabilização nos atos de gestão pública têm se tornado questões fundamentais e de suma importância na esfera pública. Frequentemente, o assunto está em pauta não apenas no Brasil, mas em vários lugares ao redor do mundo. Kondo (2002) relata o quão importante e fundamental são a responsabilização e a transparência no setor público.

De acordo com a Agência dos Estados Unidos para o Desenvolvimento Internacional (USAID), a transparência é "o esclarecimento de regras, planos, processos e ações. É saber o porquê, como, o quê e quanto" (USAID, 2013, p. 1, tradução nossa). 
A USAID (2013, p. 1, tradução nossa) ainda revela que a transparência "garante que funcionários públicos, servidores civis, gerentes, membros do conselho e empresários ajam visível e compreensivelmente, e relatem sobre suas atividades. E isso significa que o público, em geral, pode acioná-los para prestar contas".

Salienta-se, pois, que a transparência e a governança são conceitos que caminham de forma paralela, pelo fato de que a boa governança, na Administração Pública, está relacionada ao acompanhamento e ao controle das ações dos governos pela sociedade em uma democracia.

No entender de Matias-Pereira (2010, p. 118), para que exista uma boa governança há necessidade do estabelecimento de seis dimensões:

ações que assegurem uma estrutura jurídica e regulatória efetiva para as empresas estatais; ações que respaldem o papel do Estado como proprietário; tratamento igualitário de acionistas; políticas de relacionamento com os stakeholders; transparência e divulgação de informações; definição das responsabilidades dos Conselhos.

Quanto à noção de boa governança, Kondo (2002, p. 11) apresenta alguns princípios acordados de modo geral, como os descritos no Quadro 1.

\begin{tabular}{|c|c|c|}
\hline \multicolumn{3}{|c|}{ Quadro 1 - Princípios da boa governança } \\
\hline \multicolumn{2}{|c|}{ PRINCíPIOS } \\
\hline Responsabilização & Transparência & Abertura \\
\hline $\begin{array}{c}\text { É possível identificar e respon- } \\
\text { sabilizar funcionários públicos } \\
\text { por suas ações. }\end{array}$ & $\begin{array}{c}\text { Significa que informações con- } \\
\text { fiáveis, relevantes e oportunas } \\
\text { sobre as atividades do governo } \\
\text { estão disponíveis ao público. }\end{array}$ & $\begin{array}{c}\text { Os governos escutam os } \\
\text { cidadãos e as empresas, e } \\
\text { levam em conta suas sugestões } \\
\text { ao formular e implementar } \\
\text { políticas públicas. }\end{array}$ \\
\hline
\end{tabular}

Fonte: Elaborado pelos autores com base em Kondo (2002).

O Quadro 1 mostra que a boa governança, segundo Kondo (2002), decorre de correlações de princípios em que a sociedade e as empresas expressem seus anseios; as ações e informações públicas possam de fato 
estar acessíveis à população, de forma confiável; e, dessa forma, seja possível identificar e punir os descaminhos administrativos palmilhados por agentes públicos.

No contexto dos princípios de boa governança, Marques (2007, p. 14) chama atenção para a concepção de governança corporativa sob a óptica da Organização para Cooperação e Desenvolvimento Econômico (OCDE), relatando que "é o sistema pelo qual as sociedades do sector público e privado são dirigidas e controladas".

Para Marques (2007, p. 18 e 19), alguns passos devem ser observados quando se trata de atingir a efetiva governança corporativa e, assim, cita seis princípios que são: liderança, integridade, compromisso, integração, responsabilidade e transparência.

Marques (2007, p. 19-20) menciona a importância de manter a devida transparência nos atos e nas ações de gestão pública das atividades e dos atores políticos e sociais, apresentando informações de forma transparente e segura, visto que "a transparência é também essencial para ajudar a assegurar que os corpos dirigentes são verdadeiramente responsáveis, e isso é importante para uma boa governança".

A transparência das contas públicas é uma das principais questões em pauta na atualidade e na esfera da Administração Pública. Em 18 de novembro de 2011, foi sancionada a Lei $\mathrm{n}^{\circ} 12.527$, conhecida como a Lei de Acesso à Informação, para dispor de procedimentos que devem ser observados pela União, estados, Distrito Federal e municípios e, assim, garantir o acesso às informações previstas na CF de 1988 (BRASIL, 2011).

A Lei $n^{\circ} 12.527 / 2011$, no art. $3^{\circ}$, prevê o direito de acesso à informação, de acordo com os princípios básicos da Administração Pública, em observância da publicidade como regra geral, e o sigilo como exceção, tendo em vista o fomento ao desenvolvimento da cultura de transparência e do controle social da Administração Pública (BRASIL, 2011).

$\mathrm{O}$ art. 23 da Lei $\mathrm{n}^{\mathrm{o}}$ 12.527/2011 registra que as informações imprescindíveis à segurança da sociedade ou do Estado são passíveis de classifi- 
cação de sigilo desde que ponham em risco a defesa, a soberania e a integridade do território nacional; a vida, a segurança e a saúde da população; a estabilidade financeira, econômica ou monetária do país; causem risco a projetos de pesquisa e desenvolvimento científico ou tecnológico, assim como a sistemas, bens, instalações ou áreas de interesse estratégico nacional; ponham em risco a segurança de instituições ou de altas autoridades nacionais ou estrangeiras e seus familiares; e comprometam atividades de inteligência, bem como de investigação ou de fiscalização em andamento (BRASIL, 2011).

A partir do ano de 2012, o Decreto $\mathrm{n}^{\mathrm{o}} 7.724$ passou a regulamentar a Lei $n^{\circ} 12.527$, de 18 de novembro de 2011, que dispõe sobre o acesso às informações no âmbito federal (BRASIL, 2012).

De acordo com o Decreto $n^{\circ} 7.724 / 2012$, art. $1^{\circ}$, a sua função é de regulamentar, no âmbito do Poder Executivo federal, "os procedimentos para a garantia do acesso à informação e para a classificação de informações sob restrição de acesso, observados grau e prazo de sigilo [...]" (BRASIL, 2012).

Uma das questões abordadas sobre a divulgação e o acesso às informações advindas dos entes públicos é sobre os custos oriundos desses documentos, relatórios, serviços e materiais. Entretanto, o art. $4^{\circ}$ do Decreto $n^{0} 7.724 / 12$ prevê que "a busca e o fornecimento da informação são gratuitos, ressalvada a cobrança do valor referente ao custo dos serviços e dos materiais utilizados, tais como reprodução de documentos, mídias digitais e postagem" (BRASIL, 2012).

No que se refere à abrangência do Decreto $\mathrm{n}^{\circ} 7.724 / 12$, o art. $5^{\circ}$ revela que "sujeitam-se ao disposto neste Decreto os órgãos da administração direta, as autarquias, as fundações públicas, as empresas públicas, as sociedades de economia mista e as demais entidades controladas direta ou indiretamente pela União" (BRASIL, 2012).

$\mathrm{O}$ art. $6^{\circ}$ do Decreto $\mathrm{n}^{\mathrm{o}} 7.724 / 2012$ delimita o direito ao acesso às informações sobre alguns itens como informações sigilosas previstas na 
legislação, sendo do âmbito fiscal, bancário, de operações e serviços de capitais, comercial, profissional, industrial e segredo de justiça, assim como referentes a projetos de pesquisa e desenvolvimento científicos ou tecnológicos cujo sigilo seja imprescindível à segurança da sociedade e do Estado (BRASIL, 2012).

O termo transparência, no sentido literal, trata do que é transparente e/ou que se pode transparecer. Mas como esse termo pode ser tão utilizado no campo da Administração e Gestão Públicas? Gama (2017, p. 29) apresenta uma compreensão, no que concerne ao termo transparência voltado para a política, como a oportunidade que as instituições "[...] proporcionam à sociedade a capacidade de ver através de suas estruturas organizacionais".

Braga (2011, p. 52) traz o conceito acerca da transparência para o setor público, ao definir a

transparência da gestão como a atuação do órgão público no sentido de tornar sua conduta cotidiana e os dados dela decorrentes, acessíveis ao público em geral. Essa definição suplanta o conceito de publicidade previsto na Constituição Federal de 1988, pois a publicidade é uma questão passiva, de publicação de determinadas informações como requisito de eficácia. A transparência vai mais além, pois detém-se na garantia de acesso às informações de forma global, não somente aquelas que se deseja apresentar.

Vale salientar, como afirmam Cappelli, Leite e Araujo (2010, p. 100), que a transparência é um estado que apresenta gradações e características específicas e que as "[...] características de transparência são qualidades, portanto, podem ter diferentes percepções dependendo de quem for o interessado".

Cappelli, Leite e Araujo (2010, p. 100) revelam que existem cinco degraus para efetivação da transparência, que correspondem a acessibilidade, usabilidade, informativo, entendimento e auditabilidade, conforme podem ser vistos no Quadro 2. 
Quadro 2 - Degraus para efetivação da transparência

\begin{tabular}{|c|c|c|c|c|}
\hline 1 Acessibilidade & 2 Usabilidade & 3 Informativo & 4 Entendimento & 5 Auditabilidade \\
\hline $\begin{array}{l}\text { A transparência } \\
\text { é realizada pela } \\
\text { capacidade de } \\
\text { acesso. }\end{array}$ & $\begin{array}{l}\text { A transparência } \\
\text { é realizada pelas } \\
\text { facilidades de } \\
\text { uso. }\end{array}$ & $\begin{array}{l}\text { A transparência } \\
\text { é realizada pela } \\
\text { qualidade da } \\
\text { informação. }\end{array}$ & $\begin{array}{c}\text { A transparência } \\
\text { é realizada pelo } \\
\text { entendimento. }\end{array}$ & $\begin{array}{l}\text { A transparência } \\
\text { é realizada pela } \\
\text { auditabilidade. }\end{array}$ \\
\hline $\begin{array}{l}\text { Aferição de práti- } \\
\text { cas que efetivam } \\
\text { características } \\
\text { de portabilidade, } \\
\text { disponibilidade } \\
\text { e publicidade na } \\
\text { organização. }\end{array}$ & $\begin{array}{l}\text { Aferição de práti- } \\
\text { cas que efetivam } \\
\text { características } \\
\text { de uniformidade, } \\
\text { operabilidade, } \\
\text { intuitividade, } \\
\text { desempenho, } \\
\text { adaptabilidade e } \\
\text { amigabilidade na } \\
\text { organização. }\end{array}$ & $\begin{array}{l}\text { Aferição de práti- } \\
\text { cas que efetivam } \\
\text { características de } \\
\text { clareza, comple- } \\
\text { teza, corretude, } \\
\text { atualidade, } \\
\text { comparabilidade, } \\
\text { consistência, } \\
\text { integridade e } \\
\text { acurácia na } \\
\text { organização. }\end{array}$ & $\begin{array}{l}\text { Aferição de } \\
\text { práticas que efe- } \\
\text { tivam caracterís- } \\
\text { ticas de concisão, } \\
\text { compositividade, } \\
\text { divisibilidade, } \\
\text { detalhamento e } \\
\text { dependência na } \\
\text { organização. }\end{array}$ & $\begin{array}{l}\text { Aferição de } \\
\text { práticas que efe- } \\
\text { tivam caracterís- } \\
\text { ticas de validade, } \\
\text { controlabilidade, } \\
\text { verificabilidade, } \\
\text { rastreabilidade } \\
\text { e explicação na } \\
\text { organização. }\end{array}$ \\
\hline
\end{tabular}

Fonte: Elaborado pelos autores com base em Cappelli, Leite e Araujo (2010).

Embora a transparência possa ser percebida como um processo norteado por degraus "[...] é possível que características de um degrau 'superior' estejam efetivadas, sem que todas as características de um degrau 'inferior' estejam” (CAPPELLI; LEITE; ARAUJO, 2010, p. 102).

A transparência dos atos públicos respalda a construção dos hábitos adequados da gestão pública, e um dos instrumentos públicos utilizados sob essa premissa é a licitação pública. Ressalta-se que a licitação pública é uma das ferramentas que o poder público utiliza nas esferas estadual, municipal, do Distrito Federal e da União para adquirir serviços e bens, normatizados pela Lei no 8.666, de 21 de junho de 1993 (BRASIL, 1993).

A licitação pública é um instrumento de muita importância na execução das políticas de compras, gastos e aquisições dos entes públicos. De fato, a Lei $\mathrm{n}^{\circ} 8.666$ de 1993, em seu art. 3ㅇ institucionaliza que "[...] a licitação destina-se a garantir a observância do princípio constitucional da isonomia, a seleção da proposta mais vantajosa para a administração e a promoção do desenvolvimento nacional sustentável [...]" (BRASIL, 1993).

$\mathrm{O}$ art. $3^{\circ}$ da Lei $n^{\circ} 8.666 / 93$ ainda relata que a licitação deve estar 
em conformidade com "[...] os princípios básicos da legalidade, da impessoalidade, da moralidade, da igualdade, da publicidade, da probidade administrativa, da vinculação ao instrumento convocatório, do julgamento objetivo e dos que lhes são correlatos" (BRASIL, 1993).

As compras públicas de acordo com o art. 15 da Lei $n^{\circ}$ 8.666/93, nos incisos I a V, possuem condições que devem ser observadas, sendo elas: a padronização para garantir compatibilidade de especificações técnicas e de desempenho; processamento das compras pelo sistema de registro de preços; submissão às condições de aquisição em consonância com o setor privado; subdivisão para aproveitar as peculiaridades do mercado; e, por fim, orçar preços de acordo com os praticados na esfera da Administração Pública (BRASIL, 1993).

No caso de preços ou de valores monetários, a Lei $n^{\circ} 8.666 / 93$ estabelece, nos artigos 22 e 23, valores estimados para aquisição ou contratação de serviços para a esfera pública. (BRASIL, 1993). Devido às constantes variações monetárias em decorrência dos anos, os valores de contratação foram alterados primeiramente com a Lei n ${ }^{\circ}$ 9.648/1998 (BRASIL, 1998) e posteriormente em decorrência do Decreto $n^{0}$ 9.412/2018 (BRASIL, 2018), conforme pode ser visto no Quadro 3.

Quadro 3 - Valores monetários das licitações públicas

\begin{tabular}{|c|c|c|c|c|}
\hline \multirow{3}{*}{$\begin{array}{l}\text { MODALIDADE } \\
\text { DE } \\
\text { LICITAÇÃO }\end{array}$} & \multicolumn{4}{|c|}{ VALORES MONETÁRIOS DOS TIPOS DE CONTRATAÇÃO } \\
\hline & \multicolumn{2}{|c|}{ Obras e serviços de engenharia } & \multicolumn{2}{|c|}{$\begin{array}{l}\text { Compras e serviços não relaciona- } \\
\text { dos a obras e serviços de engenha- } \\
\text { ria }\end{array}$} \\
\hline & Lei $n^{0}$ 9.648/98 & $D n^{0} 9.412 / 18$ & Lei $\mathrm{n}^{0}$ 9.648/98 & $D n^{0} 9.412 / 18$ \\
\hline Convite & $\begin{array}{c}\text { Até R\$ } \\
150.000,00\end{array}$ & $\begin{array}{c}\text { Até R\$ } \\
330.000,00\end{array}$ & $\begin{array}{c}\text { Até } \\
\mathrm{R} \$ 80.000,00\end{array}$ & $\begin{array}{c}\text { Até } \\
\mathrm{R} \$ 176.000,00\end{array}$ \\
\hline $\begin{array}{l}\text { Tomada de } \\
\text { Preços }\end{array}$ & $\begin{array}{c}\text { Até } \\
\mathrm{R} \$ 1.500 .000,00\end{array}$ & $\begin{array}{c}\text { Até } \\
\mathrm{R} \$ 3.300 .000,00\end{array}$ & $\begin{array}{c}\text { Até } \\
\mathrm{R} \$ 650.000,00\end{array}$ & $\begin{array}{c}\text { Até } \\
\mathrm{R} \$ 1.430 .000,00\end{array}$ \\
\hline Concorrência & $\begin{array}{c}\text { Acima de } \\
\mathrm{R} \$ 1.500 .000,00\end{array}$ & $\begin{array}{c}\text { Acima de } \\
\mathrm{R} \$ 3.300 .000,00\end{array}$ & $\begin{array}{c}\text { Acima de } \\
\mathrm{R} \$ 650.000,00\end{array}$ & $\begin{array}{c}\text { Acima de } \\
\mathrm{R} \$ 1.430 .000,00\end{array}$ \\
\hline
\end{tabular}

Fonte: Elaborado pelos autores com base em Brasil (1998; 2018). 
Existem situações que, para aquisições e serviços na Administração Pública, não é necessário o uso da licitação, ou seja, a "dispensa de licitação", conforme previsto no art. 24 da Lei no 8.666/93 (BRASIL, 1993).

Ressalta-se que, com o advento da Lei $n^{\circ}$ 9.648/98, a dispensa de licitação está estabelecida para obras e serviços de engenharia com valor de até $10 \%$ previsto no teto $\mathrm{R} \$ 150.000,00$ na modalidade convite, até $\mathrm{R} \$ 1.500 .000,00$ na modalidade tomada de preços e concorrência. Para outros serviços e compras não relacionados às obras e aos serviços de engenharia, ficou estabelecido o valor de até $10 \%$ previsto no teto $\mathrm{R} \$$ $80.000,00$ na modalidade convite, até $\mathrm{R} \$ 650.000,00$ na modalidade tomada de preços e concorrência (BRASIL, 1998).

Vale salientar que a dispensa de licitação também é prevista na Lei $n^{\circ}$ 8.666/93, em casos de guerra ou de grave perturbação da ordem; de emergência ou de calamidade pública; quando a União precisar regular preços ou normalizar o abastecimento; quando houver casos de comprometimento de segurança nacional; para a construção, ampliação, reforma e aprimoramento das instituições penais desde que haja graves riscos à segurança pública (BRASIL, 1993).

$\mathrm{O}$ art. 25 da Lei $\mathrm{n}^{\circ}$ 8.666/93 discorre sobre situações em que há a inexigibilidade de licitação quando houver inviabilidade de competição. A Lei $n^{0} 8.666 / 93$ pode ser aplicada para aquisição de materiais, equipamentos ou gêneros que só possam ser fornecidos por produtor, empresa ou representante comercial exclusivo; contratação de serviços técnicos com profissionais ou empresas de notória especialização; contratação de profissional de qualquer setor artístico consagrado pela crítica especializada ou pela opinião pública (BRASIL, 1993).

O Decreto $\mathrm{n}^{\circ}$ 5.355, de 25 de janeiro de 2005, instituiu o Cartão de Pagamento do Governo Federal (CPGF) como uma nova forma de aquisição e de pagamento semelhantes à do setor privado de acordo com o disposto no art. 15, inciso III, da Lei no 8.666/93 (BRASIL, 2005). 
Os artigos $1^{\circ}$ e $2^{\circ}$ do Decreto $n^{\circ} 5.355 / 05$ preveem o uso do CPGF pelos órgãos e entidades da Administração Pública Federal, que integram o orçamento fiscal e a seguridade social, para pagamentos de despesas realizadas com aquisição de materiais e contratação de serviços enquadrados como suprimento de fundos. O CPGF passa a ser concebido como um instrumento de pagamento, emitido em nome da unidade gestora e operacionalizado por instituição financeira autorizada, e utilizado exclusivamente pelo portador nele identificado (BRASIL, 2005).

Ressalta-se que, em $1^{\circ}$ de fevereiro de 2008, foi instituído o Decreto $n^{0}$ 6.370, que unificou e alterou o uso de algumas atribuições do CPGF para atender a eventuais despesas, inclusive em viagens que exigiam pronto pagamento, sendo vedada a utilização do CPGF na modalidade saque, exceto do que se trata no art. 47 e decorrente de situações específicas do órgão ou entidade; vedada a abertura de conta bancária destinada à movimentação de suprimento de fundos; concessão e aplicação dos suprimentos de fundos aos órgãos essenciais da República e, por fim, a secretaria do Tesouro Nacional do Ministério da Fazenda encerra as contas bancárias destinadas a suprimentos de fundos, exceto para os órgãos citados no $1^{\circ}$ parágrafo, que são os órgãos dos Poderes Legislativo e Judiciário, do Ministério Público e da União e dos Comandos Militares (BRASIL, 2008).

O planejamento das contas públicas é peça-chave para uma boa gestão dos gastos e dos recursos públicos, bem como a antecipação de possíveis situações em que o gestor e/ou organização deve intervir e conseguir a melhor solução para lidar com essa questão. O art. $1^{\circ}$ da Lei Complementar $n^{\circ} 101$, de 4 de maio de 2000, pressupõe ações planejadas e transparentes na responsabilidade da gestão fiscal, dessa forma prevenindo riscos e desvios capazes de afetar o equilíbrio das contas e dos gastos públicos (BRASIL, 2000).

$\mathrm{O}$ art. $1^{\circ}$ da Lei Complementar $\mathrm{n}^{\mathrm{o}}$ 101/2000 ainda traz algumas situações em que se deve fazer o planejamento das aquisições públicas 
para melhor lidar com o erário e, assim, realizar o cumprimento de metas de resultados entre receitas e despesas, bem como renúncia de receitas; geração de despesas pessoais e seguridade social; dívidas consolidadas e mobiliárias; operações de crédito e antecipação de receitas, e, por fim, concessão de garantias e inscrição em Restos a Pagar. (BRASIL, 2000).

Portanto, o Portal da Transparência do Governo Federal se reveste de importância fundamental na divulgação dos resultados advindos da gestão planejada ou não, das contas públicas e, de forma simples, disponibilizar para o cidadão o acesso às informações geradas pelos atores que fazem a gestão dos recursos financeiros públicos com vistas ao controle social.

\section{PROCEDIMENTOS METODOLÓGICOS}

O Portal da Transparência do Governo Federal é uma importante ferramenta aliada ao controle social, seja na prestação de contas, seja na divulgação de gastos públicos dos entes do governo. Isso posto, esta pesquisa apresenta caráter exploratório.

Para Gil (2008, p. 27), as "pesquisas exploratórias são desenvolvidas com o objetivo de proporcionar visão geral, de tipo aproximativo, acerca de determinado fato".

No entender de Reiter (2017, p. 144, tradução nossa), a pesquisa exploratória busca

\footnotetext{
fornecer novas explicações que foram anteriormente negligenciadas e pode fazê-lo através do envolvimento ativo do pesquisador no processo de amplificação de suas ferramentas conceituais para permitir que ele ou ela levante novas questões e forneça novas explicações de uma determinada realidade, a partir de um novo ângulo.
}

Logo, ao utilizar este tipo de pesquisa, pretende-se explorar a temática genérica da transparência pública e, assim, trazer esclarecimentos sobre conceitos preconcebidos. 
Quanto à abordagem utilizada na investigação, foi baseada na pesquisa qualitativa, pois, como afirma Flick (2009), repousa em aspectos essenciais de "[...] escolha adequada de métodos e teorias convenientes; no reconhecimento e na análise de diferentes perspectivas; nas reflexões dos pesquisadores a respeito de suas pesquisas como parte do processo de produção do conhecimento [...]".

Por se tratar de estudo específico sobre o Cartão de Pagamento do Governo Federal, enquadra-se no estudo de caso, visto que o objeto é uma unidade que se analisa em profundidade (GODOY, 1995).

\subsection{DESCRIÇÃO DO UNIVERSO DA PESQUISA}

A transparência dos atos públicos se dá mediante a disponibilização, também, dos gastos públicos por meio de sítios do governo federal para aperfeiçoamento da gestão pública e como forma de divulgação das receitas e despesas realizadas na esfera pública.

Entre as diversas estruturas de divulgação de dados oficiais federais como os próprios sítios eletrônicos dos órgãos e entidades dos Poderes (Executivo, Legislativo e Judiciário), o Sistema Integrado de Administração Financeira do Governo Federal (Siafi), o Sistema Integrado de Administração de Recursos Humanos (Siape), entre outros, foi utilizado o Portal da Transparência do Governo Federal por disponibilizar informações fiscais de forma centralizada acerca de todos os Poderes nas esferas (Executivo, Legislativo e Judiciário) e órgãos da federação.

\subsection{COLETA DE DADOS}

O Portal da Transparência do Governo Federal é constituído por 12 painéis distintos que disponibilizam os seguintes dados: Orçamento, Despesas e Receitas, Órgãos, Estados e Municípios, Licitações e Contratos, Convênios, Cartões de Pagamentos, Recursos Transferidos, Benefí- 
cios aos Cidadãos, Servidores, Viagens a Serviço e Emenda Parlamentar.

Os dados foram obtidos do painel "Cartões de Pagamentos", por disponibilizarem informações a respeito do "Cartão de Pagamento do Governo Federal" (CPGF), "Cartão de Pagamento de Compras Centralizadas" (CPCC) e do "Cartão de Pagamento da Defesa Civil" (CPDC), referentes ao exercício de 2019. Os dados foram coletados no mês de setembro de 2020.

\title{
3.3 ANÁLISE DOS DADOS
}

Os dados obtidos de modo secundário foram analisados em categorias temáticas ou unidades de análise. De acordo com Pêcheux (1993, p. 65 apud CAREGNATO; MUTTI, 2006, p. 683), a análise por categorias temáticas tenta encontrar

\begin{abstract}
uma série de significações que o codificador detecta por meio de indicadores que lhe estão ligados; [...] codificar ou caracterizar um segmento é colocá-lo em uma das classes de equivalências definidas, a partir das significações, [...] em função do julgamento do codificador [...] o que exige qualidades psicológicas complementares como a fineza, a sensibilidade, por parte do codificador para apreender o que importa.
\end{abstract}

A análise de dados foi baseada nas seguintes categorias: configuração de dados, unidades de uso de CP, unidades receptoras de CP e despesas realizadas com $\mathrm{CP}$.

\section{RESULTADOS E DISCUSSÕES}

A transparência dos atos e da utilização dos recursos financeiros públicos, além de ser um ato de publicidade previsto na Constituição de 1988, é uma das formas de a gestão pública prestar contas à sociedade. Assim, o objetivo geral desta pesquisa foi analisar como o Portal da Transpa- 
rência proporciona a divulgação dos dados sobre a utilização dos recursos públicos com o uso de Cartão de Pagamento do Governo Federal como ferramenta aliada ao controle social e à prestação das contas dos gastos públicos no ano de 2019.

No que se refere à oferta de dados sobre o uso de cartão de pagamento de acordo com legislação vigente sobre a transparência pública, no Portal da Transparência do Governo Federal, os achados são os seguintes, conforme Figura 1.

Figura 1 - Organização do Portal da Transparência do Governo Federal

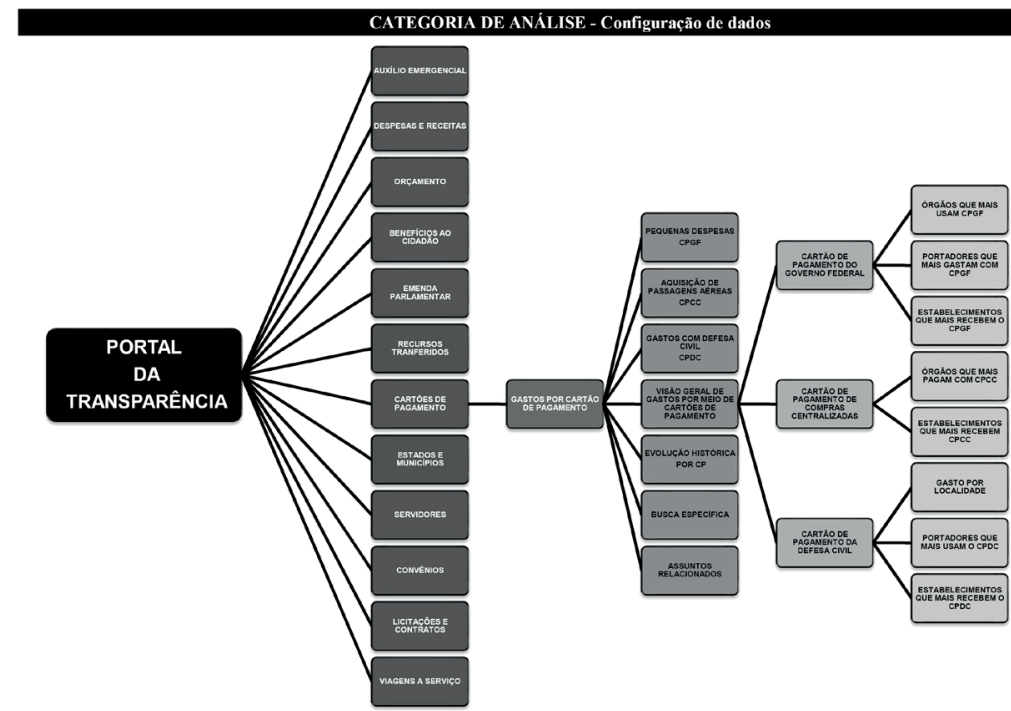

Fonte: Elaborada pelos autores com base no Portal da Transparência (2020).

De acordo com a Figura 1, o Portal da Transparência do Governo Federal, no primeiro nível, é constituído por 12 painéis que disponibilizam informações sobre o auxílio emergencial, despesas e receitas, orçamento, benefícios ao cidadão, emenda parlamentar, recursos transferidos, cartões de pagamentos, estados e municípios, servidores, convênios, licitações e contratos, e viagens a serviço. Para a pesquisa, só foi apresentado 
o segundo nível referente aos "Gastos por cartão de pagamento" por se tratar do objeto de investigação. De acordo com o item "Gastos por cartão de pagamento" do Portal da Transparência do Governo Federal, em 2019 foram gastos $\mathrm{R} \$ 268,64$ milhões por 5.306 pessoas que usaram o cartão de pagamento. Se for considerado o quantitativo de pagamento na casa dos R\$ 268 milhões pelo quantitativo de 5.306 usuários, a média será $\mathrm{R} \$ 50.508,85$ (cinquenta mil, quinhentos e oito reais, e oitenta e cinco centavos) de gasto por pessoa. O nível subsequente traz informações sobre aquisição de passagens aéreas com Cartão de Pagamento do Governo Federal (CPGF), gastos com defesa civil com o Cartão de Pagamento da Defesa Civil (CPDC), visão geral de gastos por meio de cartões de pagamento, evolução histórica por cartão de pagamento, busca específica, assuntos relacionados e, por fim, o item denominado "Pequenas despesas por meio do CPGF".

Após o item "Visão geral de gastos por meio de cartão de pagamentos", são apresentados os subníveis "Cartão de Pagamento do Governo Federal" com informações sobre órgãos que mais usam o CPGF, portadores que mais usam o CPGF e estabelecimentos que mais recebem o CPGF; o "Cartão de Pagamento de Compras Centralizadas" apresenta dados sobre órgãos que mais usam o CPCC e estabelecimentos que mais recebem o CPCC; por fim, o "Cartão de Pagamento da Defesa Civil" faz a demonstração dos gastos por localidade, os portadores que mais usam o CPDC e estabelecimentos que mais recebem o CPDC.

Tratando-se do rol de órgãos superiores e entidades vinculadas que utilizaram o cartão de pagamento em 2019, os achados podem ser vistos no Quadro 4. 
Quadro 4 - Valores e gastos por meio do CPGF

\begin{tabular}{|c|c|c|c|c|}
\hline \multicolumn{3}{|c|}{ CATEGORIA DE ANÁLISE - Unidades de uso de cartão de pagamento } \\
\hline \multicolumn{2}{|c|}{$\begin{array}{c}\text { ÓRGÃ O/ENTIDADE } \\
\text { SERVIDORES }\end{array}$} & \multicolumn{2}{c|}{$\begin{array}{c}\text { GASTOS POR MEIO DO CARTÃO DE } \\
\text { PAGAMENTO DO GOVERNO FEDERAL } \\
\text { (CPGF) }\end{array}$} \\
\cline { 3 - 5 } & Valor gasto & $\begin{array}{c}\text { Quantidade } \\
\text { de pagamento }\end{array}$ & $\begin{array}{c}\text { Quantidade } \\
\text { de portadores }\end{array}$ \\
\hline Ministério da Economia & 92.248 & $\mathrm{R} \$ 7.866 .770,92$ & 32.366 & 1.957 \\
\hline Ministério da Educação & 351.791 & $\mathrm{R} \$ 5.352 .646,00$ & 20.861 & 785 \\
\hline $\begin{array}{c}\text { Ministério da Justiça e } \\
\text { Segurança Pública }\end{array}$ & 32.350 & $10.739 .909,05$ & 13.970 & 154 \\
\hline Ministério da Defesa & 387.354 & $\mathrm{R} \$ 4.803 .497,12$ & 11.417 & 796 \\
\hline $\begin{array}{c}\text { Ministério da Agricultura, } \\
\text { Pecuária e Abastecimento }\end{array}$ & 25.252 & $\mathrm{R} \$ 2.703 .057,05$ & 9.927 & 452 \\
\hline Outros & 157.248 & $20.703 .715,97$ & 26.580 & 1019 \\
\hline
\end{tabular}

Fonte: Elaborado pelos autores com base no Portal da Transparência (2019).

O Quadro 4 apresenta os cinco maiores órgãos do Governo Federal que utilizam o CPGF. Chama a atenção, no Ministério da Justiça e Segurança Pública, a quantidade de operações de pagamento pelo número de portadores que corresponde, na média, a 90 pagamentos por pessoa durante o ano de 2019. De acordo com o Portal da Transparência, o Ministério da Educação possui 351.791 servidores com vínculo no órgão e somente 785 servidores possuem o CPGF; já o Ministério da Economia possui 92.248 servidores com vínculo no órgão, porém 1.957 servidores possuem o CPGF. Estranha-se o Ministério da Justiça e Segurança Pública, com o quarto menor número de servidores, gastar mais com o CPGF pelo fato de possuir o menor quantitativo de portadores do CPGF. Conforme o Decreto $\mathrm{n}^{\mathrm{o}}$ 6.370/2008, o uso do CPGF destina-se a atender despesas eventuais.

No Quadro 5, em seguida, é possível identificar os estabelecimentos e favorecidos que mais receberam pagamentos por meio do Cartão de Pagamento do Governo Federal no ano de 2019. 
Quadro 5 - Estabelecimentos que mais receberam por meio do CPGF

\begin{tabular}{|c|c|c|c|}
\hline \multicolumn{4}{|c|}{ CATEGORIA DE ANÁLISE - Unidades receptoras de cartão de pagamento } \\
\hline CPF/CNPJ & $\begin{array}{l}\text { NOME/RAZÃO } \\
\text { SOCIAL }\end{array}$ & $\begin{array}{l}\text { VALOR TOTAL } \\
\text { RECEBIDO }\end{array}$ & $\begin{array}{l}\text { VALOR MÉDIO } \\
\text { POR OPERAÇÃOO }\end{array}$ \\
\hline $07.575 .651 / 0001-59$ & $\begin{array}{c}\text { GOL Linhas Aéreas } \\
\text { S.A. }\end{array}$ & $\mathrm{R} \$ 688.142,39$ & $\mathrm{R} \$ 865,59$ \\
\hline 02.012.862/0001-60 & $\begin{array}{c}\text { TAM Linhas Aéreas } \\
\text { S.A. }\end{array}$ & $\mathrm{R} \$ 471.262,32$ & $\mathrm{R} \$ 773,83$ \\
\hline 09.296.295/0001-60 & $\begin{array}{c}\text { AZUL Linhas Aéreas } \\
\text { Brasileiras S.A. }\end{array}$ & $\mathrm{R} \$ 390.984,00$ & $\mathrm{R} \$ 739,10$ \\
\hline $14.625 .224 / 0001-01$ & STELO S.A. & $\mathrm{R} \$ 309.336,92$ & $\mathrm{R} \$ 353,93$ \\
\hline $16.668 .076 / 0001-20$ & $\begin{array}{c}\text { SUMUP Soluções } \\
\text { de Pagamento Brasil } \\
\text { Ltda }\end{array}$ & $\mathrm{R} \$ 164.245,30$ & $\mathrm{R} \$ 441,52$ \\
\hline $05.671 .436 / 0001-26$ & $\begin{array}{c}\text { Ana Beatriz de Fraga } \\
\text { Ferreira }\end{array}$ & $\mathrm{R} \$ 69.738,27$ & $\mathrm{R} \$ 487,68$ \\
\hline $91.269 .472 / 0001-08$ & $\begin{array}{c}\text { Pro Eletro Comercial } \\
\text { Ltda }\end{array}$ & $\mathrm{R} \$ 37.951,60$ & $\mathrm{R} \$ 632,53$ \\
\hline $09.253 .130 / 0001-00$ & $\begin{array}{c}\text { Posto de Gasolina } \\
\text { Náutico Santo Expedi- } \\
\text { to Ltda }\end{array}$ & $\mathrm{R} \$ 34.827,50$ & $\mathrm{R} \$ 2.679,04$ \\
\hline $12.103 .222 / 0001-19$ & $\begin{array}{l}\text { Castro Comercio e } \\
\text { Representações Ltda }\end{array}$ & $\mathrm{R} \$ 34.426,54$ & $\mathrm{R} \$ 1.110,53$ \\
\hline $13.057 .503 / 0001-45$ & $\begin{array}{l}\text { Adriano Silva de } \\
\text { Araujo }\end{array}$ & $\mathrm{R} \$ 33.153,00$ & $\mathrm{R} \$ 705,38$ \\
\hline
\end{tabular}

Fonte: Adaptado pelos autores com base no Portal da Transparência (2019).

O Quadro 5 elenca os estabelecimentos que mais receberam pagamentos com o CPGF. Os dados mais chamativos revelam a quantidade de gastos realizados apenas com passagens aéreas por meio das três companhias listadas. De acordo com os dados do Portal da Transparência, os pagamentos totalizaram $\mathrm{R} \$ 1.550 .388,71$ (um milhão, quinhentos e cinquenta mil, trezentos e oitenta e oito reais, e setenta e um centavos) em pagamentos de viagens aéreas ante o valor pago de $\mathrm{R} \$ 683.679,13$ (seiscentos e oitenta e três mil, seiscentos e setenta e nove reais, e treze centavos) para os demais estabelecimentos que receberam pagamentos com o 
CPGF. Ressalta-se que os gastos com as companhias aéreas são maiores do que o dobro dos valores pagos aos outros estabelecimentos durante o período de 2019.

No que tange às despesas realizadas com cartão de pagamento pelo governo federal com vistas ao controle social, os achados estão dispostos no Quadro 6.

Quadro 6 - Maiores despesas realizadas com o CPGF em 2019

\begin{tabular}{|c|c|c|c|c|c|c|c|}
\hline \multicolumn{8}{|c|}{ CATEGORIA DE ANÁLISE - Despesas realizadas com cartão de pagamento } \\
\hline $\begin{array}{l}\text { Tipo de } \\
\text { cartão }\end{array}$ & Órgão superior & $\begin{array}{l}\text { Órgão/entidade } \\
\text { vinculada }\end{array}$ & CPF portador & $\begin{array}{c}\text { Nome } \\
\text { portador }\end{array}$ & $\begin{array}{l}\text { CPF/CNPJ do } \\
\text { favorecido }\end{array}$ & $\begin{array}{c}\text { Nome do } \\
\text { favorecido }\end{array}$ & $\begin{array}{c}\text { Valor gasto no } \\
\text { período (RS) }\end{array}$ \\
\hline CPGF & $\begin{array}{c}\text { Presidência da } \\
\text { República }\end{array}$ & $\begin{array}{c}\text { Presidência da } \\
\text { República }\end{array}$ & & Sigiloso & & Sigiloso & $14.889 .017,90$ \\
\hline CPGF & $\begin{array}{l}\text { Ministério da } \\
\text { Justiça e Segu- } \\
\text { rança Pública }\end{array}$ & $\begin{array}{l}\text { Departamento de } \\
\text { Polícia Federal }\end{array}$ & & Sigiloso & & Sigiloso & $10.007 .095,03$ \\
\hline CPGF & $\begin{array}{c}\text { Presidência da } \\
\text { República }\end{array}$ & $\begin{array}{c}\text { Gabinete da } \\
\text { Vice-Presidência } \\
\text { da República }\end{array}$ & & Sigiloso & & Sigiloso & $635.351,90$ \\
\hline CPGF & $\begin{array}{c}\text { Ministério da } \\
\text { Defesa }\end{array}$ & Fundo do Exército & $* * * .641 .517$-** & $\begin{array}{c}\text { Alessandro } \\
\text { Siqueira } \\
\text { Martins }\end{array}$ & $07.575 .651 / 0001-59$ & $\begin{array}{l}\text { Gol Linhas } \\
\text { Aéreas S.A. }\end{array}$ & $231.064,25$ \\
\hline CPGF & $\begin{array}{c}\text { Ministério da } \\
\text { Economia }\end{array}$ & $\begin{array}{c}\text { Fundo Constitu- } \\
\text { cional do Distrito } \\
\text { Federal }\end{array}$ & & Sigiloso & & Sigiloso & $173.039,00$ \\
\hline CPGF & $\begin{array}{c}\text { Ministério da } \\
\text { Defesa }\end{array}$ & $\begin{array}{l}\text { Comando do } \\
\text { Exército }\end{array}$ & $* * * .715 .607-* *$ & $\begin{array}{c}\text { Artur } \\
\text { Chaves } \\
\text { Tourinho }\end{array}$ & $02.012 .862 / 0001-60$ & $\begin{array}{l}\text { Tam Linhas } \\
\text { Aéreas S/A. }\end{array}$ & $142.845,43$ \\
\hline CPGF & $\begin{array}{c}\text { Ministério da } \\
\text { Defesa }\end{array}$ & $\begin{array}{l}\text { Comando do } \\
\text { Exército }\end{array}$ & $* * * .715 .607-* *$ & $\begin{array}{c}\text { Artur } \\
\text { Chaves } \\
\text { Tourinho }\end{array}$ & $07.575 .651 / 0001-59$ & $\begin{array}{l}\text { Gol Linhas } \\
\text { Aéreas S.A. }\end{array}$ & $121.200,40$ \\
\hline CPGF & $\begin{array}{c}\text { Ministério da } \\
\text { Economia }\end{array}$ & $\begin{array}{c}\text { Ministério da } \\
\text { Economia - Uni- } \\
\text { dades com vínculo } \\
\text { direto }\end{array}$ & & Sigiloso & & Sigiloso & $115.960,00$ \\
\hline
\end{tabular}


Quadro 6 - Maiores despesas realizadas com o CPGF em 2019 (continuação)

\begin{tabular}{|c|c|c|c|c|c|c|c|}
\hline CPGF & $\begin{array}{c}\text { Ministério da } \\
\text { Ciência. Tecno- } \\
\text { logia, Inovações } \\
\text { e Comunicações }\end{array}$ & $\begin{array}{l}\text { Agência Nacional } \\
\text { de Telecomuni- } \\
\text { cações }\end{array}$ & $* * * .637 .102-* *$ & $\begin{array}{l}\text { Maria do } \\
\text { Perpetuo } \\
\text { Socorro } \\
\text { Martins } \\
\text { Machado }\end{array}$ & $07.575 .651 / 0001-59$ & $\begin{array}{l}\text { Gol Linhas } \\
\text { Aéreas S.A. }\end{array}$ & $73.914,38$ \\
\hline CPGF & $\begin{array}{l}\text { Ministério da } \\
\text { Agricultura, } \\
\text { Pecuária e } \\
\text { Abastecimento }\end{array}$ & $\begin{array}{l}\text { Ministério da } \\
\text { Agricultura, } \\
\text { Pecuária e } \\
\text { Abastecimento } \\
\text { - Unidades com } \\
\text { vínculo direto }\end{array}$ & $* * * .712 .063-* *$ & $\begin{array}{c}\text { Marcelo de } \\
\text { Andrade } \\
\text { Mota }\end{array}$ & Sem informação & Não se aplica & $67.456,63$ \\
\hline
\end{tabular}

Fonte: Adaptado pelos autores com base no Portal da Transparência (2019).

O Quadro 6 apresenta os maiores gastos realizados com o CPGF. Inicialmente, notam-se os gastos em um total de $\mathrm{R} \$ 14.889 .017,90$ (catorze milhões, oitocentos e oitenta e nove mil, dezessete reais e noventa centavos) realizados pela Presidência da República, como órgão superior e entidade vinculada, que não identifica "portador" nem "favorecido", mas o indicativo de "informações sigilosas", ou seja, não divulgado pelo Portal da Transparência. Além dessa divulgação, o terceiro gasto aponta novamente a Presidência da República como órgão superior, só que como entidade vinculada e relacionada ao Gabinete da Vice-Presidência da República; esse novo gasto possui um valor de R\$ 635.351,90 (seiscentos e trinta e cinco mil, trezentos e cinquenta e um reais, e noventa centavos). Assim como o primeiro gasto, este também não identifica "portador" nem "favorecido", e o indicativo também aponta "informações sigilosas" acerca desse gasto.

Chama-se a atenção para o que está registrado na Lei n ${ }^{\circ}$ 12.527/2011, Lei de Acesso à Informação, art. 23, de que o registro de informação sigilosa ocorre quando há risco à segurança da sociedade ou do Estado, à defesa, à soberania e à integridade do território nacional; à vida, à segurança e à saúde da população; à estabilidade financeira, econômica ou monetária do país, entre outros. 
Cabe relembrar que, de acordo com os artigos 24 e 25 da Lei $n^{\circ} 8.666 / 93$, que rege as aquisições públicas, existem situações em que ocorrem a dispensa e a inexigibilidade da licitação, entretanto se observam os valores exigidos de $10 \%$ do teto tanto na aquisição de obras e serviços de engenharia quanto nas compras e serviços não relacionados a obras e serviços de engenharia nas modalidades convite, tomada de preço e concorrência. Percebe-se que o montante de R\$14.889.017,90 (catorze milhões, oitocentos e oitenta e nove mil, dezessete reais, e noventa centavos) ultrapassa, e muito, esse valor estabelecido na lei, logo inviabiliza o uso do indicativo "sigiloso", tornando, assim, inviável a utilização do CPGF para tais tipos de gastos e demonstrando falta de planejamento financeiro. Registra-se, também, que, de acordo com o art. $1^{\circ}$ do Decreto $n^{\circ}$ 6.370/2008, prevê-se, no parágrafo único, que o CPGF é um instrumento de pagamento utilizado exclusivamente pelo portador nele identificado, nos casos indicados em ato próprio da autoridade competente e respeitados os limites desse decreto. Portanto, uma das premissas do uso do CPGF é a transparência dos gastos com ele, observando o princípio supracitado que não se encaixa nos gastos informados anteriormente.

Por outro lado, a Lei de Acesso à Informação enseja o sigilo quando a segurança de instituições ou de altas autoridades nacionais ou estrangeiras e de seus familiares for posta em risco, mas não quanto ao uso do CPGF.

Os resultados revelam que o Portal da Transparência do Governo Federal disponibiliza dados sobre a utilização do CPGF, porém existe um descompasso quanto à finalidade do uso do $\mathrm{CP}$, que é suprimento de fundos e atendimento a eventuais despesas. Por outro lado, o Ministério da Justiça e Segurança Pública, e o Ministério da Economia são os órgãos que mais gastam com o CPGF. As empresas aéreas são as mais favorecidas com o CP, e a Presidência da República, o Ministério da Justiça e Segurança Pública, e a Vice-Presidência da República são os órgãos federais que mais realizaram despesas com o CPGF no ano de 2019. 
Com esses dados, é possível notar a importância da transparência nas informações e divulgação de tais atos dos entes públicos supracitados, com a necessidade de acompanhar e fiscalizar os gastos do governo federal, pautada na urgência do controle social, mediante a fiscalização e o combate à corrupção, além da má gestão dos gastos públicos.

\section{CONSIDERAÇÕES FINAIS}

Em resposta ao problema da pesquisa sobre a forma como o Portal da Transparência do Governo Federal permite ao cidadão acompanhar a aplicação do dinheiro público federal, dispor informações para o controle social e assim promover a transparência dos gastos públicos, os achados foram os seguintes:

a) A respeito da oferta de dados sobre o uso de cartão de pagamento de acordo com legislação vigente sobre a transparência pública, o Portal da Transparência do Governo Federal disponibiliza painéis, níveis e subníveis contendo informações sobre os cartões de pagamentos utilizados na esfera federal.

b) Em relação aos órgãos superiores e entidades vinculadas que utilizaram o cartão de pagamento em 2019, percebeu-se que o Ministério da Justiça e Segurança Pública é o órgão do governo federal que mais gasta com o CPGF, com apenas 154 portadores, e o Ministério da Economia é o segundo órgão governamental a gastar mais os recursos públicos, com 1.957 portadores do CPGF, apresentando assincronia de uso em relação aos outros órgãos do governo federal com maior efetivo e unidades distribuídas no território nacional.

c) No que concerne aos estabelecimentos que mais receberam pagamentos por meio do CPGF em 2019, destacam-se três empresas aéreas que receberam R $\$ 1.550 .388,71$ (um milhão, quinhentos e cinquenta mil, trezentos e oitenta e oito reais, e setenta e um centavos) em compras de passagens aéreas. 
d) No caso das despesas realizadas com o CPGF com vistas ao controle social, a Presidência da República, o Ministério da Justiça e Segurança Pública, e a Vice-Presidência da República sempre usam para o portador e o favorecido o caráter "sigiloso" para compras cujo somatório é vultoso para um exercício anual e por meio de um cartão de pagamento.

Escrito isso, conclui-se que o Portal da Transparência do Governo Federal permite a divulgação dos gastos públicos federais e, com tal prática, é possível verificar a falta de publicidade de determinados órgãos que usam Cartão de Pagamento do Governo Federal, o descumprimento no atendimento a eventuais despesas e a ausência de planejamento no uso dos recursos públicos.

Entre as consequências advindas da ausência de planejamentos no uso dos recursos públicos tratadas no artigo, sobre o Cartão de Pagamento do Governo Federal, é possível observar que a real utilização de $\mathrm{CP}$ pelo governo não vem sendo cumprida em sua totalidade, haja vista que o CPGF deveria ser utilizado para pagamentos de pequenas despesas, suprimentos de fundos ou situações de pronto pagamento, em que não é necessário o uso de licitação, se observados os valores dispostos na Lei ${ }^{\circ}$ 9648/98.

Esta pesquisa teve caráter inicial e as informações aqui dispostas não têm finalidade de esgotar toda a temática acerca do Portal da Transparência do Governo Federal e o uso do Cartão de Pagamento do Governo Federal.

Logo, é preciso que outros pesquisadores se debrucem sobre investigações relativas ao Portal da Transparência como forma de disponibilizar para a sociedade o uso devido dos recursos financeiros públicos e disseminar a transparência dos atos realizados por entes e gestores públicos. 


\section{REFERÊNCIAS}

BRAGA, M. V. A. A auditoria governamental como instrumento de promoção da transparência. Jornal de Políticas Educacionais, Curitiba, n. 9, p. 51-60, jan./jun. 2011. Disponível em: https://revistas.ufpr.br/jpe/article/ view/25176/16823. Acesso em: 16 dez. 2019.

BRASIL. [Constituição (1988)]. Constituição da República Federativa do Brasil. Brasília, DF: Presidência da República. Disponível em: http:// www.planalto.gov.br/ccivil_03/Constituicao/ConstituicaoCompilado. htm. Acesso em: 3 ago. 2020.

BRASIL. Decreto $\mathbf{n}^{\mathbf{0}} \mathbf{5 . 3 5 5}$, de 25 de janeiro de 2005. Dispõe sobre a utilização do Cartão de Pagamento do Governo Federal - CPGF, pelos órgãos e entidades da administração pública federal direta, autárquica e fundacional, para pagamentos de despesas realizadas nos termos da legislação vigente, e dá outras providências. Disponível em: http://www. planalto.gov.br/ccivil_03/ ato2004-2006/2005/decreto/d5355.htm. Acesso em: 28 ago. 2020.

BRASIL. Decreto $\mathbf{n}^{\mathbf{0}} \mathbf{6 . 3 7 0}$, de $\mathbf{1}^{\mathbf{0}}$ de fevereiro de 2008. Altera os Decretos $n^{\circ}$ s 5.355, de 25 de janeiro de 2005, que dispõe sobre a utilização do Cartão de Pagamento do Governo Federal - CPGF, e 93.872, de 23 de dezembro de 1986, que dispõe sobre a unificação dos recursos de caixa do Tesouro Nacional, atualiza e consolida a legislação pertinente, e determina o encerramento das contas bancárias destinadas à movimentação de suprimentos de fundos. Disponível em: http:/www.planalto.gov.br/ccivil_03/_ato20072010/2008/decreto/d6370.htm. Acesso em: 28 ago. 2020.

BRASIL. Decreto $\mathbf{n}^{\mathbf{0}} \mathbf{7 . 7 2 4}$, de 16 de maio de 2012. Regulamenta a Lei $\mathrm{n}^{\mathrm{o}} 12.527$, de 18 de novembro de 2011, que dispõe sobre o acesso a infor- 
mações previsto no inciso XXXIII do caput do art. $5^{\circ}$, no inciso II do $\S$ $3^{\circ}$ do art. 37 e no $\S 2^{\circ}$ do art. 216 da Constituição. Disponível em: http:// www.planalto.gov.br/CCIVIL 03/Ato2011-2014/2012/Decreto/D7724. htm. Acesso em: 11 ago. 2020.

BRASIL. Decreto $\mathbf{n}^{\mathbf{0}} \mathbf{9 . 4 1 2}$, de 18 de junho de 2018. Atualiza os valores das modalidades de licitação de que trata o art. 23 da Lei $n^{\circ} 8.666$, de 21 de junho de 1993. Disponível em: http://www.planalto.gov.br/ccivil_03/_ Ato2015-2018/2018/Decreto/D9412.htm. Acesso em: 21 ago. 2020.

BRASIL. Lei $\mathbf{n}^{\mathbf{0}}$ 8.666, de 21 de junho de 1993. Regulamenta o art. 37, inciso XXI, da Constituição Federal, institui normas para licitações e contratos da Administração Pública e dá outras providências. Disponível em: http://www.planalto.gov.br/ccivil 03/Leis/L8666cons.htm. Acesso em: 15 ago. 2020.

BRASIL. Lei $\mathbf{n}^{\mathbf{0}} \mathbf{9 . 6 4 8}$, de 27 de maio de 1998. Altera dispositivos das Leis $n^{\circ} 3.890-A$, de 25 de abril de 1961, nº 8.666, de 21 de junho de 1993, $\mathrm{n}^{\circ} 8.987$, de 13 de fevereiro de 1995, $\mathrm{n}^{\circ}$ 9.074, de 7 de julho de 1995, $\mathrm{n}^{\circ}$ 9.427, de 26 de dezembro de 1996, e autoriza o Poder Executivo a promover a reestruturação da Centrais Elétricas Brasileiras - ELETROBRÁS e de suas subsidiárias e dá outras providências. Disponível em: http://www. planalto.gov.br/ccivil_03/leis/L9648cons.htm. Acesso em: 21 ago. 2020.

BRASIL. Lei $\mathbf{n}^{\mathbf{0}}$ 12.527, de 18 de novembro de 2011. Regula o acesso a informações previsto no inciso XXXIII do art. $5^{\circ}$, no inciso II do $\S 3^{\circ}$ do art. 37 e no $\S 2^{\circ}$ do art. 216 da Constituição Federal; altera a Lei no 8.112, de 11 de dezembro de 1990; revoga a Lei nº 11.111, de 5 de maio de 2005, e dispositivos da Lei ${ }^{\circ} 8.159$, de 8 de janeiro de 1991; e dá outras providências. Disponível em: http://www.planalto.gov.br/ccivil 03/_Ato20112014/2011/Lei/L12527.htm. Acesso em: 9 mar. 2021. 
BRASIL. Lei Complementar $\mathbf{n}^{\mathbf{0}} \mathbf{1 0 1}$, de 4 de maio de 2000. Estabelece normas de finanças públicas voltadas para a responsabilidade na gestão fiscal e dá outras providências. Disponível em: http:/www.planalto.gov. br/ccivil_03/Leis/LCP/Lcp101.htm. Acesso em: 3 ago. 2020.

BRASIL. Lei Complementar $\mathbf{n}^{\mathbf{0}} \mathbf{1 3 1}$, de 27 de maio de 2009. Acrescenta dispositivos à Lei Complementar no 101, de 4 de maio de 2000, que estabelece normas de finanças públicas voltadas para a responsabilidade na gestão fiscal e dá outras providências, a fim de determinar a disponibilização, em tempo real, de informações pormenorizadas sobre a execução orçamentária e financeira da União, dos Estados, do Distrito Federal e dos Municípios. Disponível em: http://www.planalto.gov.br/ccivil_03/Leis/ LCP/Lcp131.htm. Acesso em: 3 ago. 2020.

CAPPELLI, C.; LEITE, J. C. S. P.; ARAÚJO, R. M. A importância de um modelo de estágios para avaliar transparência. Revista TCMRJ, Rio de Janeiro, v. 27, n. 45, p. 97-103, set. 2010. Disponível em: http://www-di. inf.puc-rio.br/ julio/RevTCMRJ45.pdf. Acesso em: 21 jan. 2020.

CAREGNATO, R. C. A.; MUTTI, R. Pesquisa qualitativa: análise de discurso versus análise de conteúdo. Texto Contexto Enferm., Florianópolis, v. 15, n. 4, p. 679-684, out./dez. 2006. Disponível em: https://www. scielo.br/pdf/tce/v15n4/v15n4a17. Acesso em: 5 set 2020.

\section{CASTRO JUNIOR, O. V. Competência em informação para o uso do} Portal da Transparência do Governo Federal: requisito para um efetivo controle social das despesas públicas no Brasil. 2018. 189 f. Dissertação (Mestrado em Gestão de Unidades de Informação) - Centro de Ciências Humanas e da Educação, Universidade do Estado de Santa Catarina, Florianópolis, 2018. Disponível em: https://repositorio.cgu.gov.br/ bitstream/1/42038/5/COMPET\%c3\%8aNCIA \%20EM\%20INFORMA \%- 
c3\%87\%c3\%830\%20PARA $\% 200 \% 20$ USO $\% 20$ DO $\% 20$ PORTAL $\% 20$ DA\%20TRANSPAR\%c3\%8aNCIA\%20DO\%20GOVERNO\%20FEDERAL $\% 20-\% 20$ Requisito $\% 20$ para $\% 20$ um $\% 20$ efetivo $\% 20$ controle $\% 20$ social $\% 20$ das $\% 20$ despesas $\% 20$ p $\%$ c3\%bablicas $\% 20$ no $\% 20$ Brasil.pdf. Acesso em: 16 dez. 2019.

FLICK, U. Introdução à pesquisa qualitativa. Porto Alegre: Artmed, 2009.

FREIRE, F. R. Desafios para a transparência pública: um estudo com os usuários do Portal da Transparência do Governo Federal. 2014. 284 f. Dissertação (Mestrado em Ciência Política) - Universidade de Brasília, Brasília, DF, 2014. Disponível em: https://repositorio.unb.br/bitstream/10482/17107/1/2014_FelipeRibeiroFreire.pdf. Acesso em: 20 dez. 2019.

GAMA, J. R. Transparência pública e governo eletrônico: análise dos portais dos municípios do Pará. Belém: Núcleo de Altos Estudos Amazônicos, 2017. Disponível em: https://livroaberto.ufpa.br/jspui/bitstream/ prefix/573/1/Livro TranparenciaPublicaGovernoEletronico.pdf. Acesso em: 16 dez. 2019.

GAMA, J. R.; RODRIGUES, G. M. Transparência e acesso à informação: um estudo da demanda por informações contábeis nas universidades federais brasileiras. TransInformação, Campinas, v. 28, n. 1, p. 47-57, jan./abr. 2016. Disponível em: https://www.scielo.br/pdf/tinf/v28n1/01033786-tinf-28-01-00047.pdf. Acesso em: 17 dez. 2019.

GIL, A. C. Métodos e técnicas de pesquisa social. São Paulo: Atlas, 2008. 
GODOY, A. S. Pesquisa qualitativa: tipos fundamentais. Revista de Administração de Empresas, São Paulo, v. 35, n. 3, p. 20-29, maio/jun. 1995. Disponível em: https:/www.scielo.br/scielo.php?script=sci_arttext\&pid=S0034-75901995000300004. Acesso em: 8 abr. 2021.

\section{Guimarães, E. M. A difusão da política de Transparência Pública}

no Brasil: a atuação da Controladoria-Geral da União no estado do Espírito Santo. 2019. 170 f. Tese (Doutorado em Sociologia Política) - Centro de Ciências do Homem, Universidade Estadual do Norte Fluminense Darcy Ribeiro, Campos dos Goytacazes, 2019. Disponível em: https://repositorio.cgu.gov.br/bitstream/1/33212/10/Tese_Edyvar_Guimaraes.pdf. Acesso em: 23 dez. 2019.

KONDO, S. Promovendo o diálogo para fortalecer a boa governança. In: KONDO, S. et al. Transparência e responsabilização no setor público: fazendo acontecer. Brasília: MPOG: SEGES, 2002. Disponível em: http:// conscienciafiscal.mt.gov.br/arquivos/A_5080f64a35dc452d5e6ffe35ed18350cTransparenciaeresponsabilisacaonosetorpublico.pdf. Acesso em: 16 dez. 2019.

MARQUES, M. C. C. Aplicação dos princípios da governança corporativa ao sector público. Revista de Administração Contemporânea, Maringá, v. 11, n. 2, p. 11-26, abr./jun. 2007. Disponível em: https://www.scielo.br/ pdf/rac/v11n2/a02v11n2.pdf. Acesso em: 8 set. 2020.

MATIAS-PEREIRA, J. A governança corporativa aplicada no setor público brasileiro. Revista APGS: Administração Pública e Gestão Social, Viçosa, v. 2, n. 1, p. 110-135, jan./mar. 2010. Disponível em: https://repositorio.unb.br/handle/10482/5974. Acesso em: 13 out. 2020. 
MICHENER, G.; CONTRERAS, E.; NISKIER, I. Da opacidade à transparência? Avaliando a Lei de Acesso à Informação no Brasil cinco anos depois. RAP: Revista de Administração Pública, Rio de Janeiro, v. 52, n. 4, p. 610-629, jul./ago. 2018. Disponível em: https://www.scielo.br/pdf/ rap/v52n4/pt_1982-3134-rap-52-04-610.pdf. Acesso em: 16 dez. 2019.

PORTAL DA TRANSPARÊNCIA. Gastos por cartões de pagamentos. Disponível em: http://www.portaltransparencia.gov.br/cartoes?ano=2019. Acesso em: 2 set. 2020.

PORTAL DA TRANSPARÊNCIA. Portal da Transparência (2020). Disponível em: http://www.portaltransparencia.gov.br/. Acesso em: 2 set. 2020.

REITER, B. Theory and methodology of exploratory social science research. Ijsrm.Human,v. 5, n. 4, p. 129-150, Feb. 2017. Disponível em: http://ijsrm.humanjournals.com/wp-content/uploads/2017/03/10.Bernd-Reiter.pdf. Acesso em: 8 set. 2020.

USAID. Transparency and accountability: RATE summary. USAID: Nathan Associates Inc., 2013. Disponível em: https://www.usaid.gov/sites/default/files/documents/1861/Transparency and_Accountability.pdf. Acesso em: 20 out. 2020. 